\title{
LIAPUNOV FUNCTIONS FOR NEURAL NETWORK MODELS
}

\author{
MÁRTON NEOGRÁdY-KiSS AND PÉTER L. SiMON*
}

\begin{abstract}
The dynamical behaviour of continuous time recurrent neural network models is studied with emphasis on global stability of a unique equilibrium. First we show in a unified context two Liapunov functions that were introduced in the nineties by Hopfield, Grossberg, Matsouka and Forti. Then we introduce a class of networks for which the model becomes a special cooperative system with a unique globally stable steady state. Finally, we show that periodic orbits may occur when the sufficient conditions for the existence of Liapunov functions are violated.
\end{abstract}

Mathematics subject classification (2020): 34D23, 34C25, 92B20.

Keywords and phrases: Global stability, Hopfield model, periodic orbit.

\section{REFERENCES}

[1] P. Ashwin And S. Coombes AND R. Nicks, Mathematical frameworks for oscillatory network dynamics in neuroscience, J. Math. Neuroscience, 6 (1), 2, (2016).

[2] R. D. BEER, On the dynamics of small continuous-time recurrent neural networks, Adaptive Behavior 3 (4), 469-509, (1995).

[3] R. D. BEER, Parameter space structure of continuous-time recurrent neural networks, Neural Computation 18 (12), 3009-3051, (2006).

[4] Á Bodó AND P. L. Simon, Transcritical bifurcation yielding global stability for network processes, Nonlinear Analysis (2020).

[5] B. ERmentrout, Neural networks as spatio-temporal pattern-forming systems, Reports on progress in physics 61 (4), 353, (1998).

[6] B. ERmentrout And D. H. Terman, Foundations of mathematical neuroscience, Springer Berlin, 2010.

[7] D. Fasoli And A. CATTANi And S. PANZeri, The complexity of dynamics in small neural circuits, PLoS computational biology 12 (8), e1004992, (2016).

[8] M. FORTI, On global asymptotic stability of a class of nonlinear systems arising in neural networks theory, J. Diff. Equ., 113 (1), 246-264, 1994.

[9] S. Grossberg, Nonlinear neural networks: Principles, mechanisms, and architectures, Neural networks 1 (1), 17-61, (1988).

[10] JoHn J. HopfiELD, Neurons with graded response have collective computational properties like those of two-state neurons, PNAS 81 (10), 3088-3092, (1984).

[11] Jiang Ji-FA, On the Global Stability of Cooperative Systems, Bull. London Math. Soc., 26 (5), 455458, 1994.

[12] J. KENNAN, Uniqueness of positive fixed points for increasing concave functions on $\mathbb{R}^{n}$ : An elementary result, Review of Economic Dynamics, Elsevier for the Society for Economic Dynamics, 4 (4), 893-899, 2001.

[13] A. LAJMANOVICHKE AND J. A. YORKE, A deterministic model for gonorrhea in a nonhomogeneous population, Math. Biosci. 28, 221-236, (1976).

[14] Kiyotoshi Matsuoka, Stability conditions for nonlinear continuous neural networks with asymmetric connection weights, Neural Networks 5 (3), 495-500, (1992).

[15] L. M. Pecora and F. Sorrentino and A. M. Hagerstrom and T. E. Murphy and R. Roy, Cluster synchronization and isolated desynchronization in complex networks with symmetries, Nature communications 5, 4079, (2014). 
[16] H. L. SMith, Monotone Dynamical Systems: An Introduction to the Theory of Competitive and Cooperative Systems, American Mathematical Society, 2008.

[17] T. TRAPPEnBERG, Fundamentals of computational neuroscience, OUP Oxford, 2009.

[18] H. ZHANG AND Z. WANG AND D. LIU, A comprehensive review of stability analysis of continuoustime recurrent neural networks, IEEE Transactions on Neural Networks and Learning Systems, 25 (7), 1229-1262, (2014). 